Ting May Lin, Then Siew Ping, Agus Saptoro*, and Panau Freddie

\title{
Mass Transfer Coefficients and Correlation of Supercritical Carbon Dioxide Extraction of Sarawak Black Pepper
}

\begin{abstract}
Bioactive compound, namely piperine, was extracted from Sarawak black pepper using supercritical carbon dioxide extraction. Experiments were carried out in the range of 3,000-5,000 psi (20.7-34.4 MPa) pressures, 318-328 K temperatures, 0.4-1 mm mean particle sizes and 5-10 $\mathrm{ml} / \mathrm{min}$ carbon dioxide flow rates. Experimental data analysis shows that extraction yield is mainly influenced by pressure, particle size and coupled-interactions between these two variables. Extraction process was modeled accounting for intraparticle diffusion and external mass transfer. The kinetics parameters for the internal and external mass transfers were evaluated and estimated. Mass transfer correlation was also developed. From simulation results, good agreement between experimental and simulated data has been found.
\end{abstract}

Keywords: Sarawak black pepper, supercritical fluid extraction, mass transfer coefficients, mass transfer correlation

*Corresponding author: Agus Saptoro, Department of Chemical and Petroleum Engineering, Curtin University, Miri, Sarawak, Malaysia Department of Chemical Engineering, National Institute of Technology (ITENAS), Bandung, West Java, Indonesia, E-mail: agus.saptoro@curtin.edu.my; saptoroa@itenas.ac.id Ting May Lin: E-mail: 7D6A3728@stud.curtin.edu.my, Then Siew Ping: E-mail: then.sp@curtin.edu.my, Panau Freddie: E-mail: freddie.p@curtin.edu.my, Department of Chemical and Petroleum Engineering, Curtin University, Miri, Sarawak, Malaysia

\section{Introduction}

Pepper, being the "King of Spices," is invariably popular as an ingredient in sauces, seasonings and condiments. Among the best peppers in the world, Malaysian pepper is one of them. Pepper has been cultivated in Malaysia for more than 100 years and this agricultural crop has placed Malaysia as one of the leading pepper producer in the world. The state of Sarawak accounts for $95 \%$ of Malaysia total production [1] and this figure is about 25,000 tones annual production rate. Generally, there are two main types of peppers produced in Sarawak: black and white peppers (Figure 1(b) and 1(c)) where black pepper contributes to $70 \%$ to $75 \%$ of the total production of Sarawak pepper [1].

Black pepper (Piper Nigrum L. (fam. Piperaceae)) is derived from the pepper plant as shown in Figure 1(a). It is a large woody vine where it can grow to the heights of more than 30 feet in the hot and humid climates. The benefits of black pepper are believed exceeding far beyond its ability to add great taste to a wide variety of dishes. Some scientific studies suggested that black pepper may have a number of important health benefits and one of the most important benefits is its ability to improve digestive system and promote intestinal health $[3,4]$. Moreover, recent research indicates that piperine, the major bioactive compound in the black pepper extracts, may act as antidepressant, antioxidant, antiproliferative and a pain-relief agent [5]. Additionally, black pepper also contains approximately $2 \%-6 \%$ essential oil [1], where it plays a major role in the manufacture of perfumery and confectionery products. Therefore, the extracted oils of black pepper have sufficient resources for nutraceutical medicines and specialty chemicals.

Beside its promising medical benefits above, another advantage of having black pepper oil is that it can be stored easily and safely than ground pepper [5]. Hence, there is much interest in its extraction and recovery procedures. Steam distillation has traditionally been applied for essential oils recovery from plant materials. However, the use of these hydrodistillation methods, involving high temperature process, may cause chemical alteration of the compounds and these heat-sensitive compounds can be easily affected. Hence, the quality of the extract is severely impaired [6-9].

Other alternative methods to isolate heat-sensitive natural active compounds are solvent extraction techniques using organic solvents such as hexane or dichloromethane. However, the massive wide scale use of organic solvents as separation (extraction) agents by a diverse of global industries have been viewed as a serious threat to the environment. Consequently, there are pressures for industry to 


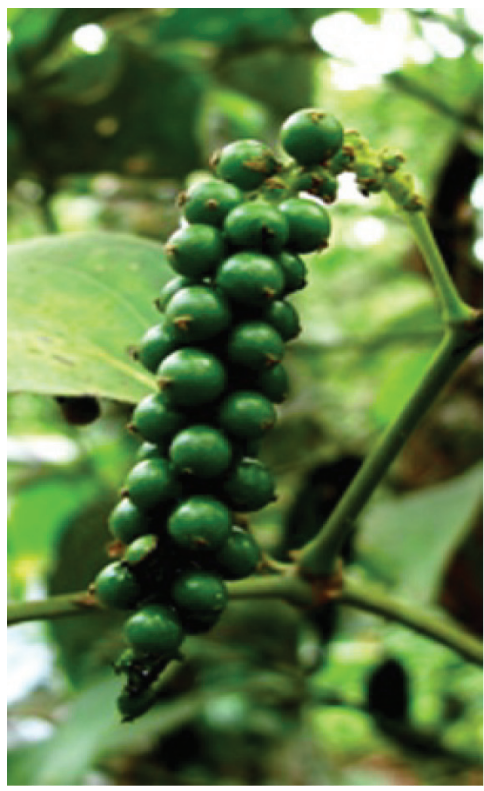

(a)

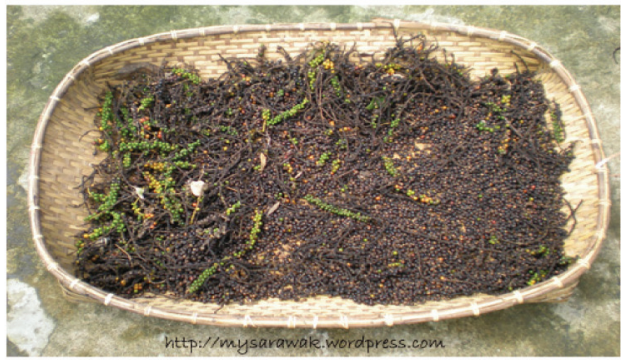

(b)

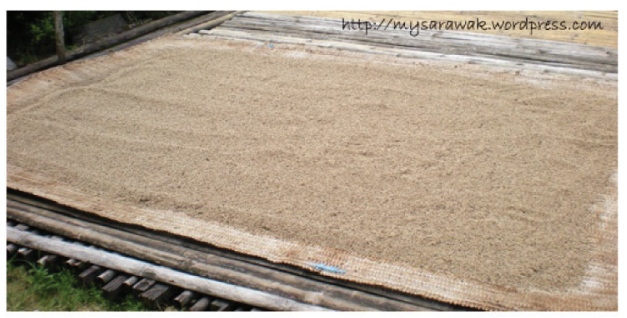

(c)

Figure 1 Pictures of pepper berries and black and white peppers [2]. (a) Pepper berries. (b) Black Pepper. (c) White pepper

adopt new sustainable process which do not require the use of environmentally damaging organic solvents. In this regard, supercritical fluid extraction has been sought as an alternative to the conventional extraction methods. Supercritical fluid extraction is an attractive technique because of its effectiveness, rapidness and non-toxicness. The use of supercritical fluids, especially carbon dioxide, in the extraction of plant volatile components has increased during the past two decades due to the expected advantages of the supercritical extraction process above. Therefore, nowadays, supercritical fluid extraction technique has gained popularity in bioactive compounds recovery from plant materials as indicated by numerous publications in the past 10 years [6-14]. These include isolation and recovery of bioactive compounds from black pepper.

Extraction of bioactive compounds from pepper is a series of mass transfer processes. The mechanisms of these mass transfer processes consist of two main steps: internal and external mass transfers. Internal transfer is the diffusion of bioactive compounds from the interior sides to the surface of the solid particle of pepper. Then, the compounds cross the particle film, separating the particle surface from the fluid, travel to the fluid phase and diffuse within the flow of the fluid phase in the supercritical extraction bed (external transfer). These mechanisms can be represented by kinetic mathematical models and they can be solved to obtain the kinetics parameters (mass transfer coefficients). These appropriate models and the kinetics parameters can be utilized to facilitate the scale-up from laboratory data into industrial design.

A number of researchers have conducted supercritical carbon extraction of black pepper [1, 15-23]. Among these existing works, few efforts also have been made in addressing mass transfer modeling and kinetics of supercritical carbon dioxide extraction of black pepper oil [17-21]. However, despite their promising results on the modeling and kinetics studies, most of these works only focus on finding mass transfer coefficients. To date, the publications on the establishment of mass transfer correlation for supercritical fluid extractions are limited to extraction of wood [24], roasted peanut oil [25], evening primrose $[25,26]$, rapeseed, rosehip seed and olive husk [27], valerian root oil [28], microalgae [29] and palm oil kernel [30]. Meanwhile, publications of mass transfer correlation for black pepper oil extraction using supercritical fluid are very scarce. Therefore, in this work, experimental study and an integrated mass transfer modeling in finding both mass transfer coefficients and correlation are presented.

\section{Experimental}

\subsection{Materials}

Ground black peppers with mean diameters of $0.4 \mathrm{~mm}$, $0.8 \mathrm{~mm}$ and $1 \mathrm{~mm}$ were obtained from Malaysia Pepper 
Board. Physical properties of the different types of black pepper are shown in Table 1. The carbon dioxide used in this study was supplied by Eastern Oxygen Industrial Sdn. Bhd., with a purity of $99.99 \%$.

Table 1 Physical properties of different types of Sarawak black pepper [1]

\begin{tabular}{llrr}
\hline Types of black pepper & Source & $\begin{array}{r}\text { Essential } \\
\text { oil, wt\% }\end{array}$ & $\begin{array}{r}\text { Density, } \\
\mathbf{g} / \mathbf{c m}^{\mathbf{3}}\end{array}$ \\
\hline $\begin{array}{c}\text { Low-density Sarawak } \\
\text { pepper }\end{array}$ & $\begin{array}{l}\text { Malaysia/Sarawak } \\
\text { pepper board } \\
\begin{array}{c}\text { High-density Sarawak } \\
\text { pepper }\end{array}\end{array}$ & $3-6$ & 0.9301 \\
\hline
\end{tabular}

\subsection{Apparatus}

The apparatus used in the experiment is a bench-scale apparatus of Supercritical Fluid Technology Model 100 as shown in Figure 2. It consists of a dual pistol pump producing high pressures required for supercritical fluid work, a $100 \mathrm{ml}$ extraction chamber with 12,000 psi of design pressure and a restrictor valve providing precise control over $\mathrm{CO}_{2}$ flow rate. The liquid $\mathrm{CO}_{2}$ is circulated through a pre-heating coil where it is heated to a supercritical condition depending on the operating pressure set in the extraction column. $\mathrm{CO}_{2}$ rapidly diffuses into the porous particles, dissolves the bioactive compounds and moves across a resistant film between the solid surface and the bulk liquid.

\subsection{Methods}

In a typical experimental run, $40 \mathrm{~g}$ of ground Sarawak black pepper was placed into the extraction vessel. Fiber glass wool (thickness $=5 \mathrm{~mm}$ ) was also placed on both sides of the column to prevent tubing blockage. Leak test was performed to every nozzle of the tubing system before the experiment. The column was then heated and pressurized to the particular parameters. Static extraction was carried out by soaking the pepper particle in supercritical $\mathrm{CO}_{2}$ for 10 minutes. Saturated $\mathrm{CO}_{2}$ was drained out by twisting the restrictor valves while the solvent was continuously pumped to the chamber with specified flow rate to maintain the pressure set point. Amber collecting vial was used to collect the extracted oil as bioactive compounds are sensitive to light. The collection steps were completed when the solvent was drained out with analyte and the column was re-pressurized for the next cycles of experiments. The collected extract was weighted at the end of each cycle. The process was ended when the increment of solute mass is less than $0.15 \mathrm{wt} \%$.

Experiments were performed for various coupling of parameters: pressures of $20.7 \mathrm{MPa}(3,000 \mathrm{psi}), 27.6 \mathrm{MPa}$ (4,000 psi) and $34.4 \mathrm{MPa}(5,000 \mathrm{psi})$; temperatures of 318

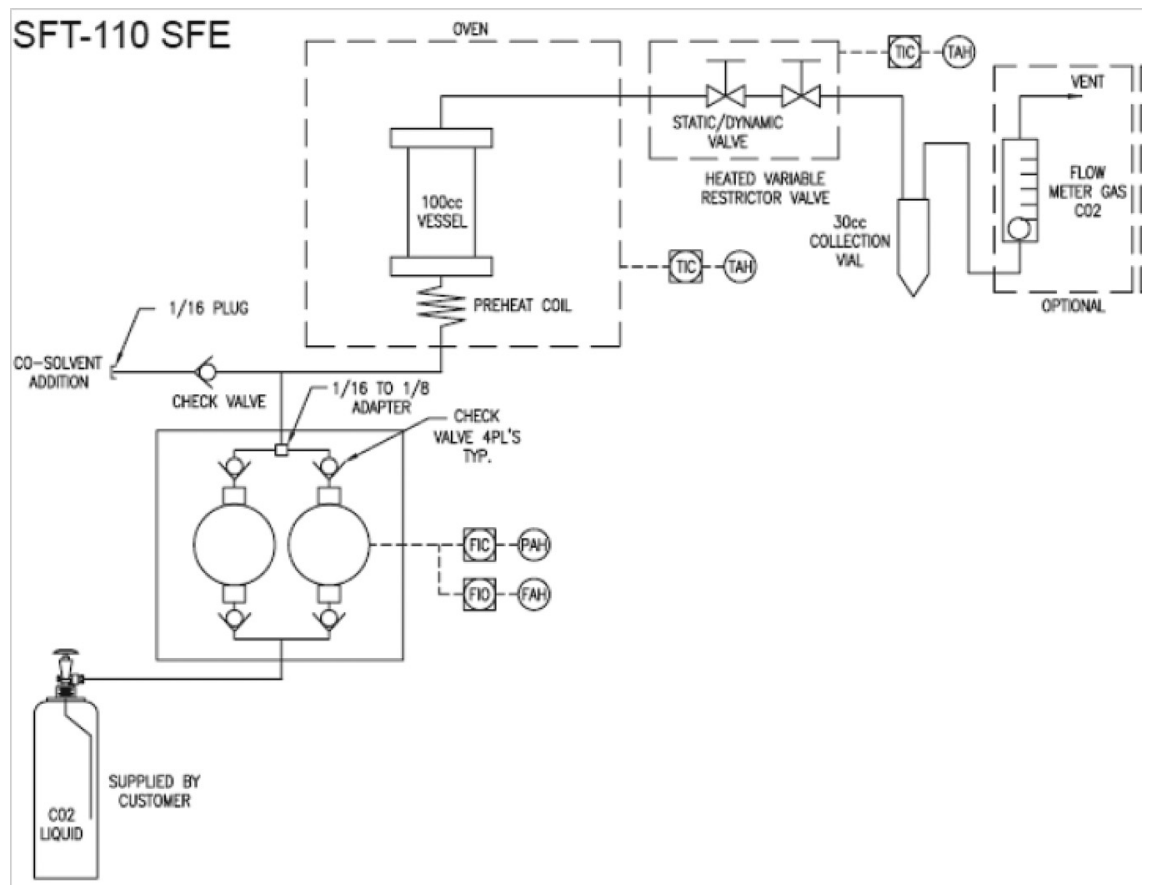

Figure 2 Schematic diagram of experimental apparatus and setup for liquid carbon dioxide extraction [31] 
$\mathrm{K}\left(45^{\circ} \mathrm{C}\right), 323 \mathrm{~K}\left(50^{\circ} \mathrm{C}\right)$ and $328 \mathrm{~K}\left(55^{\circ} \mathrm{C}\right)$; mean particle sizes of $0.4 \mathrm{~mm}, 0.8 \mathrm{~mm}$ and $1 \mathrm{~mm}$; and solvent flow rates of $5 \mathrm{ml} / \mathrm{min}, 7.5 \mathrm{ml} / \mathrm{min}$ and $10 \mathrm{ml} / \mathrm{min}$.

\section{Experimental results}

\subsection{Extraction curve}

To develop extraction curve, experiments were conducted until constant mass of solute in the extract is reached. The extraction yield was plotted against extraction time to obtain an extraction curve as shown in Figure 3. The curve was then compared with the extraction curves from Zhiyi et al. [21] and it is evident that all curves indicate similar patterns. As seen in this figure, it is obvious that the extraction process consists of three periods of extractions, and these are consistent with extraction curves from other literatures [19, 32].

(i) Constant extraction rate (CER): At this period, extraction of easily accessible oil occurs. Therefore, the highest extraction rate is achieved at this period as represented by the highest slope compared with slopes in other regions. Mass transfers mainly depend on the solute solubility on those particular operating conditions.

(ii) Falling extraction rate period (FER): The extraction rate begins to decelerate due to depletion of the easily accessible oil at the early stage of the fixed bed column. (iii) Diffusion-controlled period (DC): Solvent diffuses into porous particle to dissolve the compounds trapped in the solid substratum and then backdiffuses the dissolved compounds to the solvent. DC period is continued until the entire bioactive compounds in the solid particle is extracted. Low extraction rate is observed as represented by a flat line (almost constant extraction rate).

\subsection{Statistical analysis}

Design-Expert Software was used to perform statistical analysis of the experimental results. Two-factor interaction model was selected to present the extraction yield. Eq. (1) illustrated the experimental results by considering linear effect and two-factor interaction of the parameters, where $T$ is temperature in ${ }^{\circ} \mathrm{C}, P$ is pressure in psi, $Q$ is $\mathrm{CO}_{2}$ flow rate in $\mathrm{ml} / \mathrm{min}$ and $d_{p}$ is particle size in $\mathrm{mm}$.

$$
\begin{aligned}
\text { Extraction yield }= & 1.824-0.036 \mathrm{~T}+4.901 \times 10^{-4} \mathrm{P} \\
& -0.202 \mathrm{Q}-1.56 d_{p}-3.92 \times 10^{-6} \mathrm{TP} \\
& +3.271 \times 10^{-3} \mathrm{TQ}+0.038 \mathrm{Td}_{p} \\
& +1.36955 \times 10^{-5}-2.54 \times 10^{-4} \mathrm{Pd}_{p} \\
& +2.73 \times 10^{-3} Q d_{p}
\end{aligned}
$$

The analysis of variance (ANOVA) for linear model with interaction terms for each parameter, namely temperature $(T)$, pressure $(P)$, solvent flow rate $(Q)$ and

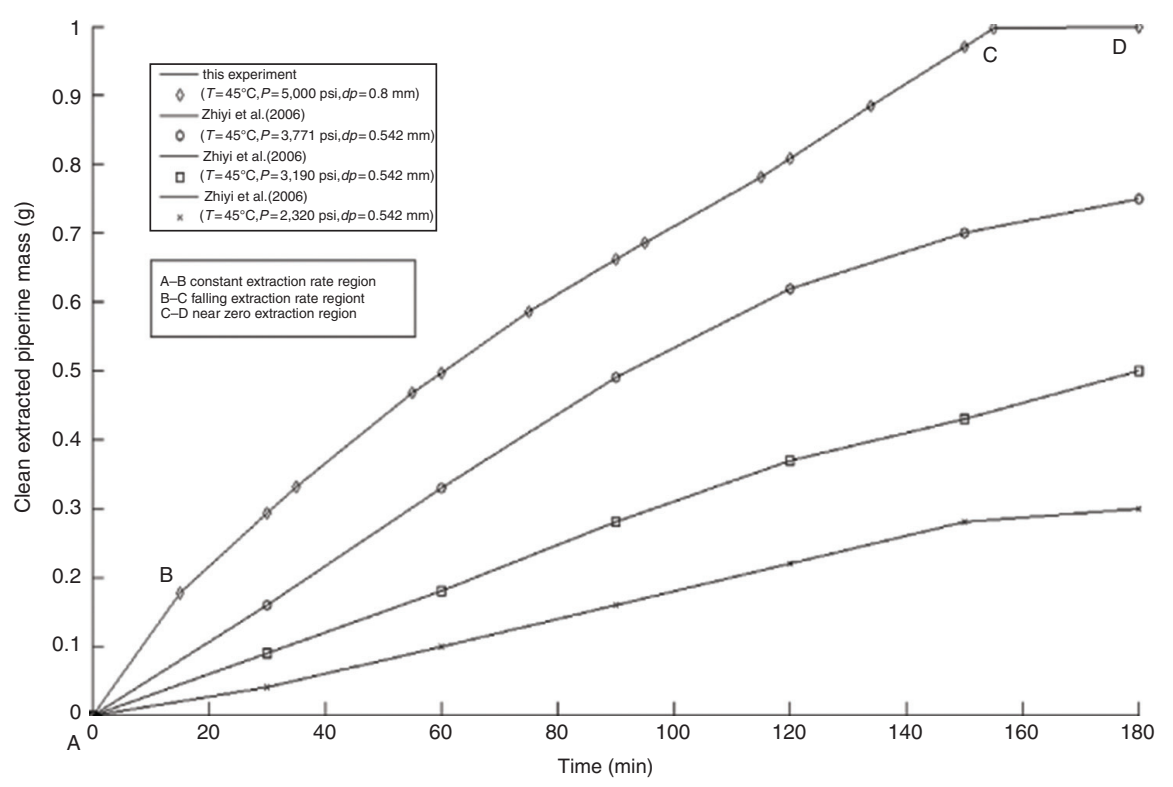

Figure 3 Extraction curve 
Table 2 ANOVA of the experimental data

\begin{tabular}{llrlrr}
\hline Source & Sum of squares & $\begin{array}{r}\text { Degree of } \\
\text { freedom }\end{array}$ & Mean square & F-value & $P$-value \\
\hline Model & 1.71 & 10 & 0.17 & 26.23 & $<0.0001$ \\
$T$ & $1.46 \times 10^{-4}$ & 1 & $1.46 \times 10^{-4}$ & 0.022 & 0.8826 \\
$P$ & 0.85 & 1 & 0.85 & 130.19 & $<0.0001$ \\
$Q$ & 0.036 & 1 & 0.036 & 5.57 & 0.0297 \\
$d_{p}$ & 0.73 & 1 & 0.73 & 112.01 & $<0.0001$ \\
$T P$ & $4.112 \times 10^{-3}$ & 1 & $4.112 \times 10^{-3}$ & 0.63 & 0.4368 \\
$T Q$ & 0.018 & 1 & 0.018 & 2.76 & 0.1142 \\
$T d_{p}$ & 0.036 & 1 & 0.036 & 5.54 & 0.0302 \\
$P Q$ & 0.013 & 1 & 0.013 & 1.93 & 0.1815 \\
$P d_{p}$ & 0.065 & 1 & 0.065 & 9.94 & 0.0055 \\
$Q d_{p}$ & $4.656 \times 10^{-5}$ & 1 & $4.656 \times 10^{-5}$ & $7.161 \times 10^{-3}$ & 0.9335 \\
Residual & 0.12 & 18 & $6.501 \times 10^{-3}$ & & 0.1348 \\
Lack of fit & 0.12 & 17 & $6.872 \times 10^{-3}$ & 33.68 & \\
Pure error & $2 \times 10^{-4}$ & 1 & $2.04 \times 10^{-4}$ & & \\
\hline
\end{tabular}

particle size $\left(d_{p}\right)$ and their two-factor combinations toward the extraction yield is presented in Table 2. It is analyzed that $P, Q, d_{p}, T d_{p}$ and $P d_{p}$ are the significant factors with confidence level $>95 \%$. ANOVA in Table 1 also indicates that operating pressure and black pepper particle size are two main influencing variables (represented by their mean squares are much greater than $P$-values), followed by $P d_{p}$ interaction. Meanwhile, solvent flow rate and $T d_{p}$ interaction have the moderate influences to the extraction process.

\section{Mathematical modeling}

The following assumptions were used to develop the process models [21]: (i) Uniform pepper particle size in spherical shape was used. (ii) All the components to be extracted behave similarly in the mass transfer and therefore could be described by a single component called the "solute." (iii) $\mathrm{CO}_{2}$ flows uniformly through every section of the extractor. Pressure drop and temperature gradients within the column were neglected. (iv) Volume of concrete remains the same. (v) Pepper oil in the mobile phase is the function of time and height of the extractor.

Flow diagram for a packed bed extraction column, internal structure of the solid particle and concentration profile of the solute within particle and fluid film can be seen in Figure 4. In this work, the kinetic mathematic models were derived based on the two main mechanisms taken place during oil extraction processes: internal and external mass transfers.

\subsection{Internal mass transfer model}

Internal mass transfer phenomenon is illustrated by Figure 5. According to mass balance theory

$$
\begin{aligned}
& \left\{\begin{array}{c}
\text { Rate of } \\
\text { solute mass in }
\end{array}\right\}-\left\{\begin{array}{c}
\text { Rate of } \\
\text { solute mass out }
\end{array}\right\} \\
& +\left\{\begin{array}{c}
\text { Rate of generation } \\
\text { of solute mass }
\end{array}\right\}=\left\{\begin{array}{c}
\text { Rate of accumulation } \\
\text { of solute mass. }
\end{array}\right\}
\end{aligned}
$$

Since there is no mass generation during the process, therefore the terms rate of generation of solute mass is equal to zero. Eq. (2) becomes

$\left\{\begin{array}{c}\text { Rate of } \\ \text { solute mass in }\end{array}\right\}-\left\{\begin{array}{c}\text { Rate of } \\ \text { solute mass out }\end{array}\right\}=\left\{\begin{array}{c}\text { Rate of } \\ \text { accumulation }\end{array}\right\}$

The internal mass transfer model then can be obtained by applying Fick's law of diffusion on eq. (3):

$$
\frac{\partial C_{p}}{\partial t}=\left(-D_{e} \frac{\partial C_{p}}{\partial r}\right)\left(4 \pi r^{2}\right)-\left(-D_{e} \frac{\partial C_{p}}{\partial r}\right)\left[4 \pi(r+\Delta r)^{2}\right]
$$

Rearrange eq. (4) and divide it by $\Delta r^{2}$ :

$$
\frac{\partial C_{p}}{\partial t}=\frac{\left(D_{e} \frac{\partial C_{p}}{\partial r}\right)\left[4 \pi(r+\Delta r)^{2}\right]-\left(D_{e} \frac{\partial C_{p}}{\partial r}\right)\left(4 \pi r^{2}\right)}{\Delta r^{2}}
$$

Taking the limit as $\Delta r \rightarrow 0$ gives the final internal mass balance equation:

$$
\frac{\partial C_{p}}{\partial t}=\frac{D_{e}}{r^{2}} \frac{\partial}{\partial r}\left(r^{2} \frac{\partial C_{p}}{\partial r}\right)
$$




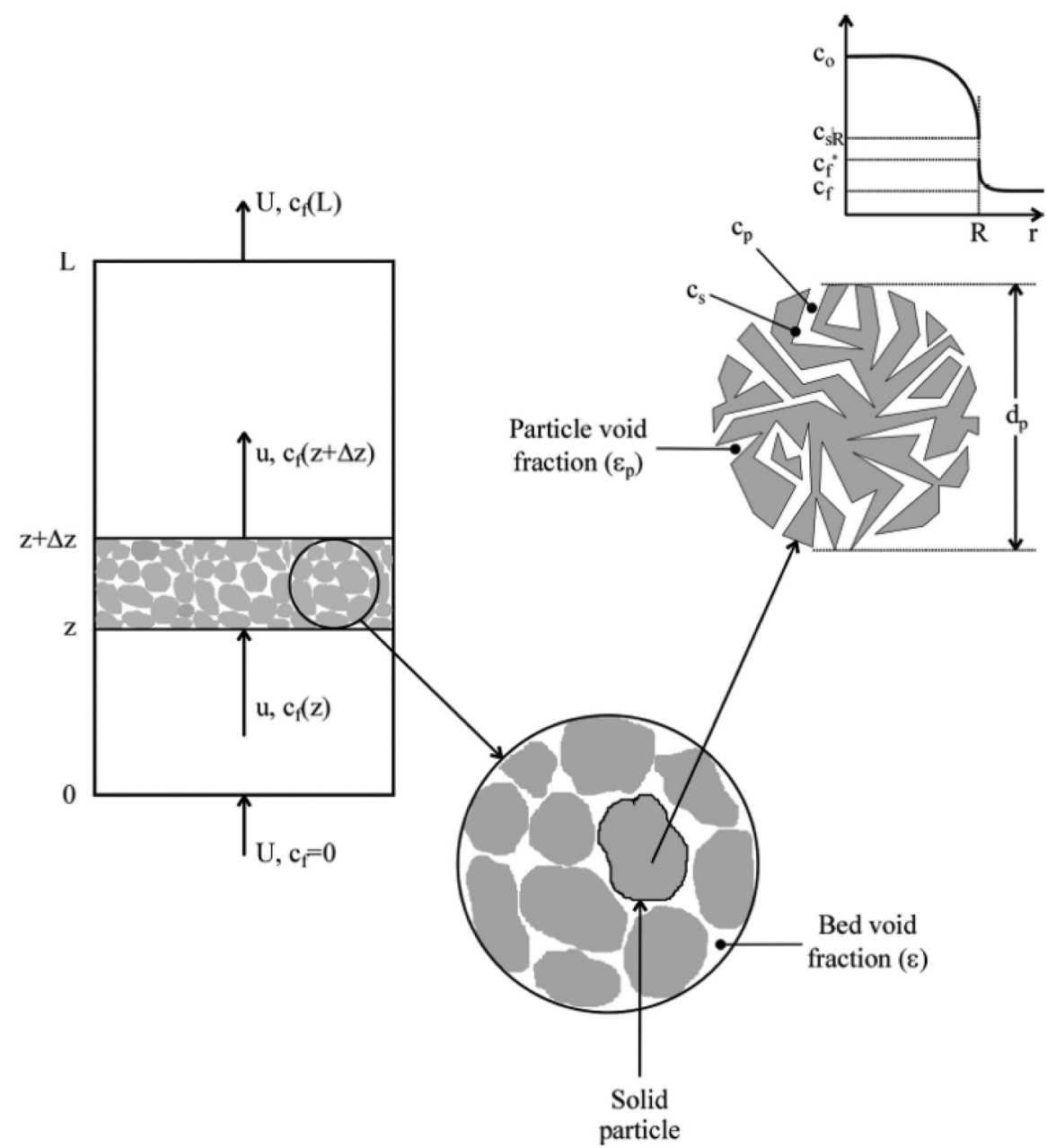

Figure 4 Flow diagram for a packed bed extraction column, internal structure of the solid particle and concentration profile of the solute within particle and fluid film [33]

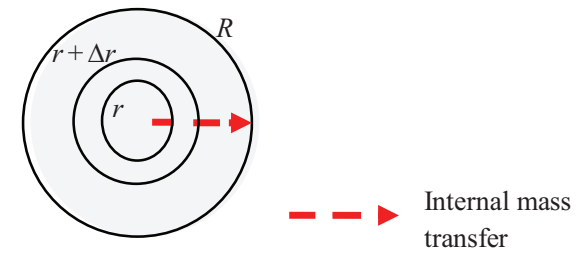

Figure 5 Pepper particle model for internal mass transfer

On the assumption that initially the solvent is solute free and all particles have same initial solute content, then the boundary conditions for the system are:

$$
\begin{gathered}
\frac{\partial C_{p}}{\partial r}=0 \text { at } r=0 \\
\left(D_{e} \frac{\partial C_{p}}{\partial r}\right)=k_{c}\left[C_{f}-C_{p}\right] \text { at } r=R
\end{gathered}
$$

\subsection{External mass transfer model}

External mass transfer of pepper oil can be described as the movement of pepper oil outside the solid particle as shown in Figure 6. This external mass transfer consists of two processes: mass transfer of solute from the surface of particle to the solvent by convection and diffusion of pepper oil in the bulk flow of solvent.

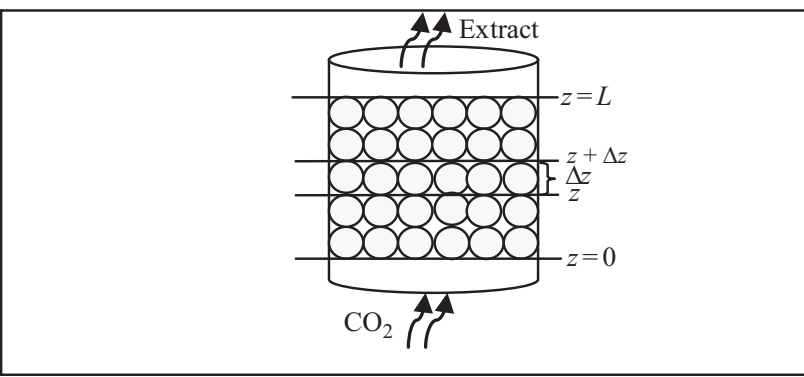

Figure 6 External mass transfer process 
By assuming that only diffusion to axial direction ( $z$-direction) is significant and $\mathrm{A}$ is the cross-sectional area of the column, hence, mass balance of external mass transfer applied in the control volume $A$. $\Delta z$, is

$$
\begin{aligned}
& \left\{\begin{array}{c}
\text { Rate of solute mass in } \\
\text { and out by convection }
\end{array}\right\}+\left\{\begin{array}{c}
\text { Rate of solute mass in } \\
\text { and out by diffusion }
\end{array}\right\} \\
& +\left\{\begin{array}{c}
\text { Rate of mass transfer } \\
\text { across the film to solvent }
\end{array}\right\} \\
& =\left\{\begin{array}{c}
\text { Rate of accumulation } \\
\text { of solute mass. }
\end{array}\right\}
\end{aligned}
$$

By applying Fick's law of diffusion and steady-state process occurs, eq. (9) becomes

$$
\begin{gathered}
\left(\left.u A C_{f}\right|_{z}-\left.u A C_{f}\right|_{z+\Delta z}\right)+\left[\left.\left(-D_{L} A \frac{\partial C_{f}}{\partial z}\right)\right|_{z}-\left.\left(-D_{L} A \frac{\partial C_{f}}{\partial z}\right)\right|_{z+\Delta z}\right] \\
-\left[\frac{1-\varepsilon}{\varepsilon} \Delta z A \frac{3 k_{c}}{R}\left(C_{f}-C_{p}\right)\right]=u A \frac{\partial C_{\mathrm{f}}}{\partial \mathrm{t}}
\end{gathered}
$$

By rearranging eq. (10), dividing it by $A$. $\Delta z$ and taking the limit as $\Delta z \rightarrow 0$, the final external mass balance equation is:

$$
\frac{\partial C_{f}}{\partial t}+u \frac{\partial C_{f}}{\partial z}=D_{L} \frac{\partial^{2} C_{f}}{\partial z^{2}}-\left[\frac{1-\varepsilon}{\varepsilon} \frac{3 k_{c}}{R}\left(C_{f}-C_{p}\right)\right]
$$

The initial conditions given as follows:

$$
C_{f}=0 \text { at } t=0
$$

Meanwhile, boundary conditions at the inlet of column as well as at the outlet condition are as follows [34]:

$$
\begin{gathered}
u C_{f}-D_{L} \frac{\partial C_{f}}{\partial z}=0 \text { at } z=0 \\
\frac{\partial C_{f}}{\partial z}=0 \text { at } z=L
\end{gathered}
$$

For the purpose of simplicity, it is easier to analyze variables in the differential equations above in dimensionless form. Therefore, several dimensionless groups are defined [34].

$$
\begin{aligned}
& X_{f}=\frac{C_{f}}{C_{\mathrm{sat}}}, \quad X_{p}=\frac{C_{p}}{C_{\mathrm{sat}}}, \quad \xi=\frac{r}{R}, \quad Z=\frac{z}{L}, \\
& a=\frac{u R^{2}}{D_{e} L}, \quad \theta=\left(\frac{D_{e}}{R^{2}}\right) t, \quad \mathrm{Pe}=\frac{u L}{D_{L}}, \quad \mathrm{Bi}=\frac{k_{c} R^{2}}{D_{e} L}
\end{aligned}
$$

With these dimensionless groups, eq. (6) becomes

$$
\frac{\partial X_{p}}{\partial \theta}=\frac{1}{\xi^{2}} \frac{\partial}{\partial \xi}\left(\xi^{2} \frac{\partial \mathrm{X}_{\mathrm{p}}}{\partial \xi}\right)
$$

and its dimensionless boundary conditions are

$$
X_{p}=1 \text { at } \xi=\xi_{c}
$$

$$
\left(\frac{\partial X_{p}}{\partial \xi}\right)_{\xi=1}=\operatorname{Bi}\left[X_{f}-X_{p}(1)\right]
$$

Meanwhile, eq. (11) becomes

$$
\frac{\partial X_{f}}{\partial \theta}+a \frac{\partial X_{f}}{\partial Z}=\frac{a}{\operatorname{Pe}} \frac{\partial^{2} X_{f}}{\partial Z^{2}}-\left[\frac{1-\varepsilon}{\varepsilon} \frac{3 \operatorname{Bi}\left(X_{f}-1\right)}{1-\operatorname{Bi}\left(1-\frac{1}{\xi_{c}}\right)}\right]
$$

and its dimensionless boundary conditions are

$$
\begin{gathered}
X_{f}=0 \text { at } \theta=0 \\
X_{f}-\frac{1}{\operatorname{Pe}} \frac{\partial X_{f}}{\partial Z}=0 \text { at } Z=0 \\
\frac{\partial X_{f}}{\partial Z}=0 \text { at } Z=1
\end{gathered}
$$

\subsection{Finite difference approximation}

The dimensionless partial differential models in eqs. (16) and (19) need to be numerically solved by applying finite differential analysis (FDA). Through FDA using CrankNicolson method, the matrix forms of the partial differential equation can be obtained and by using initial and boundary conditions they are solved to obtain solute concentrations within the solid and extract. CrankNicolson method was chosen since it performs better than explicit and implicit approaches [35]. The matrix forms of FDA analyses for eqs. (16) and (19) are shown as follows. Eq. (16) becomes

$$
\begin{array}{r}
{\left[1+\frac{2 \Delta \xi}{\xi}\right]\left(X_{p i+1, j+1}\right)+\left[-2-\frac{2\left(\Delta \xi^{2}\right)}{\Delta \theta}\right]\left(X_{p i, j+1}\right)} \\
\quad+\left[1-\frac{2 \Delta \xi}{\xi}\right]\left(X_{p i-1, j+1}\right)=-\left[1+\frac{2 \Delta \xi}{\xi}\right]\left(X_{p i+1, j}\right) \\
\quad-\left[-2+\frac{2\left(\Delta \xi^{2}\right)}{\Delta \theta}\right]\left(X_{p i, j}\right)-\left[1-\frac{2 \Delta \xi}{\xi}\right]\left(X_{p i-1, j}\right)
\end{array}
$$

and eq. (19) becomes

$$
\begin{aligned}
& {\left[\frac{a}{\mathrm{Pe}}-a(\Delta Z)\right]\left(X_{f} i+1, j+1\right)} \\
& \quad+\left[-2 \frac{a}{\mathrm{Pe}}-\left(\Delta Z^{2}\right) C-2 \frac{\left(\Delta Z^{2}\right)}{\Delta \theta}\right]\left(X_{f} i, j+1\right) \\
& \quad+\left[\frac{a}{\mathrm{Pe}}+a(\Delta Z)\right]\left(X_{f} i-1, j+1\right)=-\left[\frac{a}{\mathrm{Pe}}-a(\Delta Z)\right]\left(X_{f} i+1, j\right) \\
& \quad-2 \frac{a}{\mathrm{Pe}}-\left(\Delta Z^{2}\right) C+2 \frac{\left(\Delta Z^{2}\right)}{\Delta \theta}\left(X_{f i, j}\right) \\
& \quad\left[\frac{a}{\mathrm{Pe}}+a(\Delta Z)\right]\left(X_{f i-1, j}\right)-\left[2\left(\Delta Z^{2}\right) C\right]
\end{aligned}
$$




\subsection{Mass transfer coefficients}

Using experimental data, eqs. (23) and (24) were solved simultaneously to obtain predicted solute concentration in the solid's pore and extract. To do so, three coefficients in the square brackets [] need to be determined first. These coefficients are important mass transfer coefficients: the effective molecular diffusion coefficient within the solid $\left(D_{e}\right)$, convective mass transfer coefficient from solid surface to the solvent $\left(k_{c}\right)$ and axial diffusivity coefficient of solute in the solvent $\left(D_{L}\right)$. External mass transfer coefficient $\left(k_{c}\right)$ was determined by trial-and-error method which is outlined in Figure 7 . These procedures were performed using MATLAB 7.1 software.

The effective molecular diffusion coefficient, $D_{e}\left(\mathrm{~m}^{2} / \mathrm{s}\right)$, can be estimated using [8]:

$$
D_{e}=\frac{D_{12} \varepsilon_{p}}{2-\varepsilon_{p}}
$$

where $D_{12}$ is the molecular diffusion coefficient $\left(\mathrm{m}^{2} / \mathrm{s}\right)$ and $\varepsilon_{p}$ is the internal particle porosity.

The molecular diffusion coefficient, $D_{12}$ can be calculated using the Wilke and Chang equation [34]:

$$
D_{12}=1.173 \times 10^{-13} \frac{(\beta M)^{0.5} T}{\mu V^{0.6}}
$$

where $\beta$ is the solvent association constant, $M$ is the molar mass of solvent $(\mathrm{kg} / \mathrm{kmol}), T$ is the solvent temperature $(K), \mu$ is the solvent viscosity $\left(\mathrm{mNs} / \mathrm{m}^{2}\right)$ and $V$ is the solute molar volume at boiling point $\left(\mathrm{m}^{3} / \mathrm{kmol}\right)$.

For axial diffusion of solute in the solvent, dispersion coefficient, $D_{L}$ is formulated as follows [34]:

$$
D_{L}=\frac{u_{z} d_{p}}{\varepsilon \mathrm{Pe}}
$$

where Pe is the Peclet number which can be calculated by:

$$
P_{e}=\frac{0.2}{\varepsilon}+\frac{0.011}{\varepsilon}(\varepsilon \operatorname{Re})^{0.48}
$$

Lastly, overall mass transfer coefficient $\left(k_{p}\right)$ is sometimes preferable rather than individual coefficients such as $D_{e}, k_{c}$ and $D_{L}$. This overall mass transfer coefficient, $k_{p}$, is estimated according to Zhiyi et al. [21]:

$$
k_{p}=\frac{5 k_{c}}{5+\mathrm{Bi}}
$$

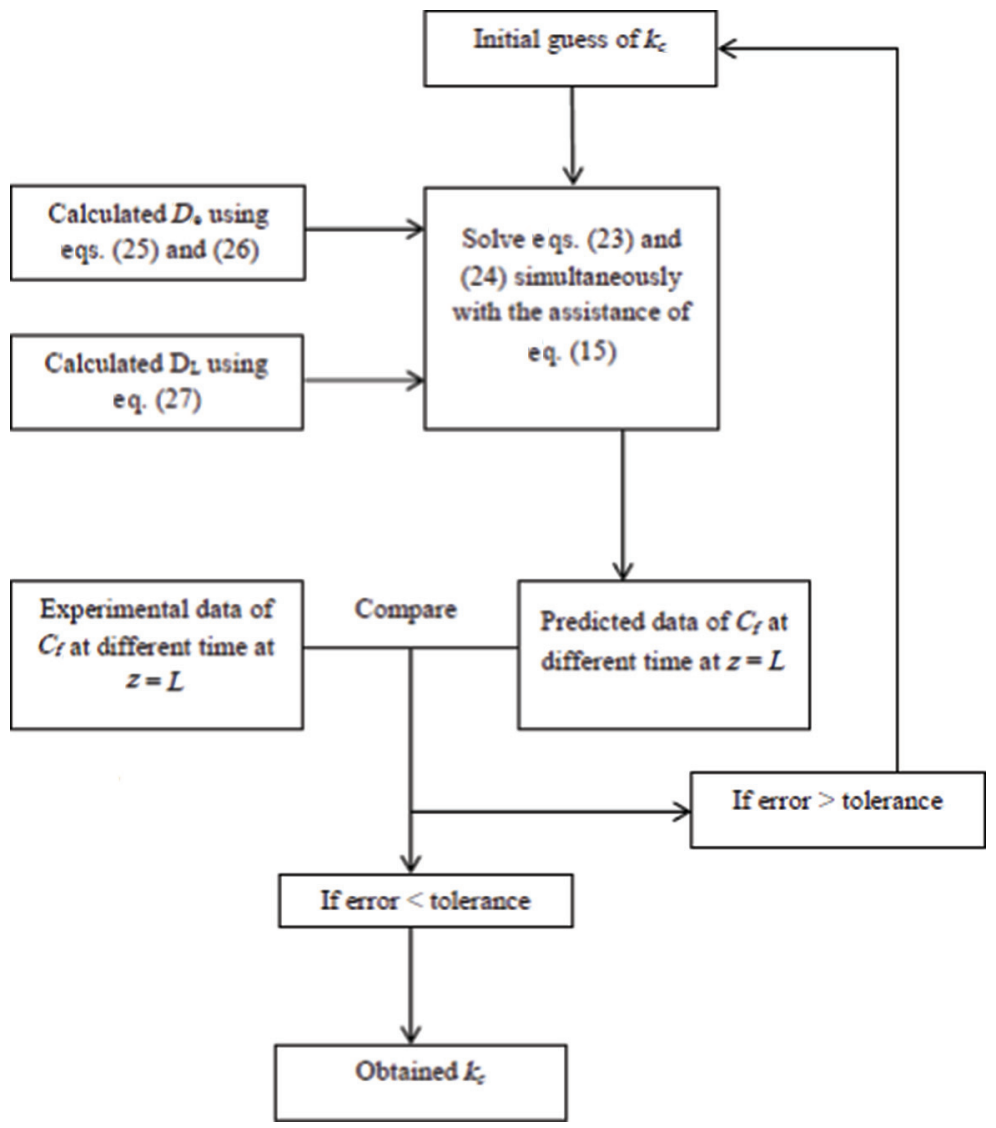

Figure 7 Procedures to obtained external mass transfer coefficient $\left(k_{c}\right)$ 
with

$$
\mathrm{Bi}=\frac{k_{c} R}{D_{e}}
$$

\section{Simulation results and discussion}

Modeling and simulation were performed by solving eqs. (23) and (24). Parameters and constants used in these modeling and simulations are summarized in Tables 3 and 4.

Table 3 Parameters used in modeling and Simulation (interpolated from data provided by Macías-Sánchez et al. [29])

\begin{tabular}{lccc}
\hline $\boldsymbol{P , p s i}$ & $\boldsymbol{T},{ }^{\circ} \mathrm{C}$ & $\boldsymbol{\rho}, \mathbf{k g} / \mathrm{m}^{3}$ & $\boldsymbol{\mu}, \mathrm{kg} / \mathrm{m.s}$ \\
\hline 3,000 & 45 & 817.4036 & $7.6 \times 10^{-5}$ \\
& 50 & 789.9508 & $7.11 \times 10^{-5}$ \\
& 55 & 760.1348 & $6.67 \times 10^{-5}$ \\
4,000 & 45 & 871.8662 & $8.6 \times 10^{-5}$ \\
& 50 & 849.9286 & $8.21 \times 10^{-5}$ \\
& 55 & 827.0066 & $7.84 \times 10^{-5}$ \\
5,000 & 45 & 913.1463 & $9.58 \times 10^{-5}$ \\
& 50 & 894.7122 & $9.18 \times 10^{-5}$ \\
& 55 & 876.0018 & $8.81 \times 10^{-5}$ \\
\hline
\end{tabular}

Table 4 Constants used in modeling and simulation

\begin{tabular}{|c|c|c|}
\hline Constant & Symbol & Value \\
\hline Solvent association constant* & $B$ & \\
\hline Solvent molar mass $(\mathrm{kg} / \mathrm{kmol})^{\star}$ & $M$ & 44.01 \\
\hline Piperine density $\left(\mathrm{kg} / \mathrm{m}^{3}\right)^{\star \star}$ & $\rho_{p}$ & 1,193 \\
\hline Piperine molar mass $(\mathrm{kg} / \mathrm{kmol})^{\star \star}$ & $M_{p}$ & 285.34 \\
\hline Internal porosity & $\varepsilon_{p}$ & 0.3 \\
\hline Column cross-sectional area $\left(\mathrm{m}^{2}\right)$ & $A$ & $7.07 \times 10^{-4}$ \\
\hline Bed height (m) & $L$ & 0.14 \\
\hline Internal diameter of the column (m) & $D$ & 0.03 \\
\hline Bed voidage ${ }^{\star \star \star \star}$ & $E$ & 0.4 \\
\hline
\end{tabular}

Source: *Geankoplis [36], **Wikipedia [37], ${ }^{\star \star \star * Z h i y i ~ e t ~ a l . ~[21], ~}{ }^{\star \star \star \star \star G o t o ~}$ et al. [34].

\subsection{Mass transfer coefficients}

The values of the estimated mass transfer coefficients are summarized in Table 5.

The values are consistent with the data from Araus et al. [38], de Valle and de Fuente [33], Ndocko et al. [8], de Valle et al. [27], Fiori [39], Spricigo et al. [40], Salimi et al. [28] and Uquiche et al. [41], where typical effective diffusion coefficients for different systems of plant materials origin are in the range of $10^{-13}$ and $10^{-7}$. Therefore, the results from this work are within the range and considered acceptable. The values of $k_{c}$ and $D_{L}$ are also comparable with the ones found in other similar systems. Table 6

Table 5 Mass transfer coefficients

\begin{tabular}{|c|c|c|c|c|c|}
\hline Operating conditions & $D_{12}, \mathrm{~m}^{2} / \mathrm{s}$ & $D_{e}, \mathrm{~m}^{2} / \mathrm{s}$ & $k_{c}, \mathrm{~m} / \mathrm{s}$ & $k_{p}, \mathrm{~m} / \mathrm{s}$ & $\overline{D_{L}, \mathrm{~m}^{2} / \mathrm{s}}$ \\
\hline $\begin{array}{l}T=45^{\circ} \mathrm{C} \\
P=5,000 \mathrm{psi} \\
d_{p}=0.8 \mathrm{~mm} \\
Q=5 \mathrm{ml} / \mathrm{min}\end{array}$ & $1.24 \times 10^{-9}$ & $2.52 \times 10^{-10}$ & $2.38 \times 10^{-4}$ & $1.17 \times 10^{-5}$ & $5.45 \times 10^{-5}$ \\
\hline $\begin{array}{l}T=55^{\circ} \mathrm{C} \\
P=4,000 \mathrm{psi} \\
d_{p}=0.4 \mathrm{~mm} \\
Q=7.5 \mathrm{ml} / \mathrm{min}\end{array}$ & $1.15 \times 10^{-9}$ & $2.35 \times 10^{-10}$ & $4.22 \times 10^{-4}$ & $2.83 \times 10^{-5}$ & $4.38 \times 10^{-5}$ \\
\hline $\begin{array}{l}T=55^{\circ} \mathrm{C} \\
P=5,000 \mathrm{psi} \\
d_{p}=0.4 \mathrm{~mm} \\
Q=5 \mathrm{ml} / \mathrm{min}\end{array}$ & $1.22 \times 10^{-9}$ & $2.47 \times 10^{-10}$ & $3.24 \times 10^{-4}$ & $2.49 \times 10^{-5}$ & $3.08 \times 10^{-5}$ \\
\hline $\begin{array}{l}T=45^{\circ} \mathrm{C} \\
P=3,000 \mathrm{psi} \\
d_{p}=0.8 \mathrm{~mm} \\
Q=10 \mathrm{ml} / \mathrm{min}\end{array}$ & $9.82 \times 10^{-10}$ & $2.00 \times 10^{-10}$ & $3.78 \times 10^{-4}$ & $1.49 \times 10^{-5}$ & $9.68 \times 10^{-5}$ \\
\hline $\begin{array}{l}T=50^{\circ} \mathrm{C} \\
P=4,000 \mathrm{psi} \\
d_{p}=1 \mathrm{~mm} \\
Q=7.5 \mathrm{ml} / \mathrm{min}\end{array}$ & $1.08 \times 10^{-9}$ & $2.2 \times 10^{-10}$ & $2.87 \times 10^{-4}$ & $1.11 \times 10^{-5}$ & $9.13 \times 10^{-5}$ \\
\hline
\end{tabular}




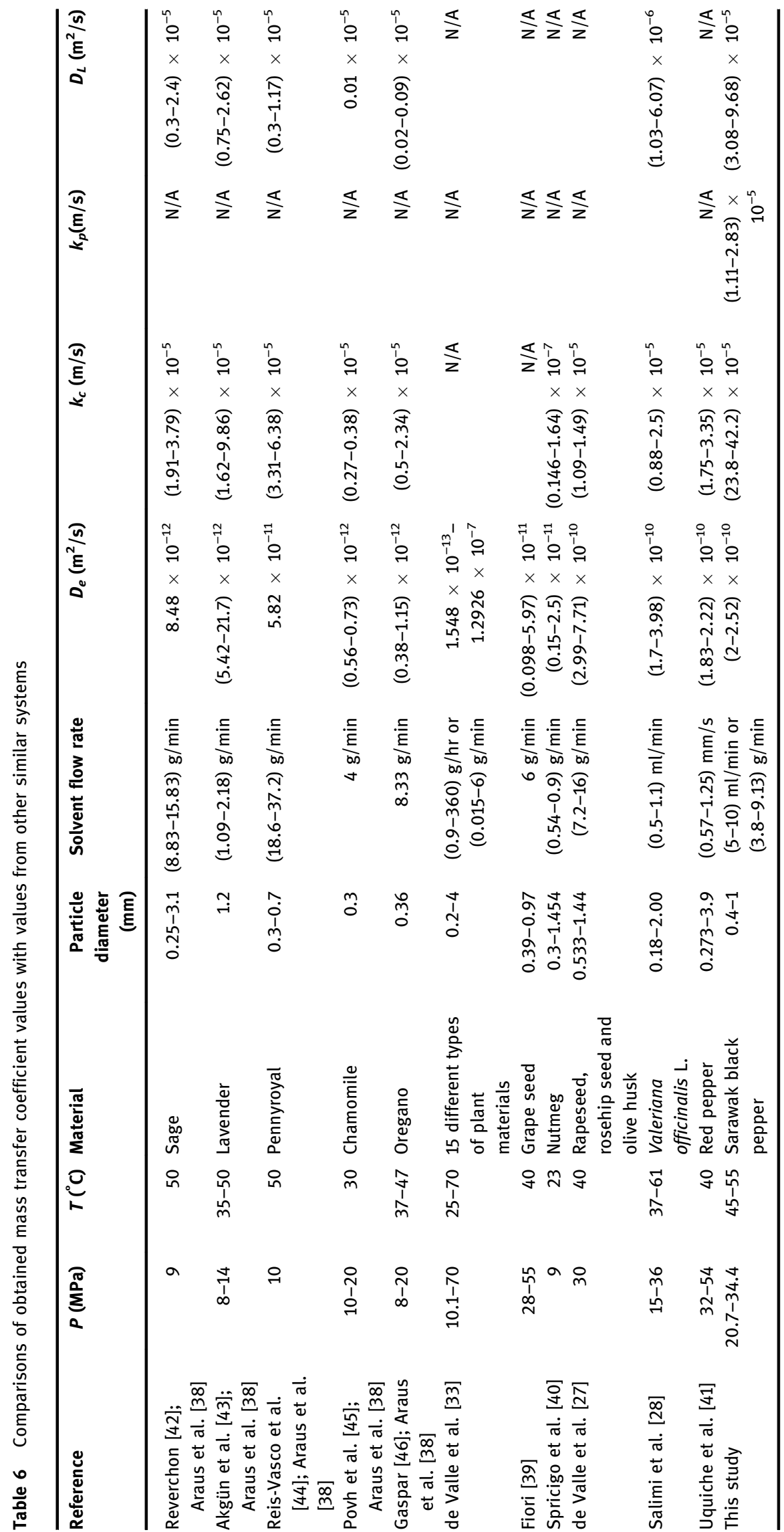


summarizes comparisons of mass transfer coefficient values obtained from this study and other works.

From the tables above, it is also evident that the values of both internal $\left(D_{12}\right.$ and $\left.D_{e}\right)$ and external $\left(k_{c}\right.$ and $D_{L}$ ) mass transfer coefficients varies depending on operating conditions. Therefore, optimal operating conditions are essential to ensure the optimal extraction processes.

\subsection{Mass transfer correlations}

There are few existing mass transfer correlations for supercritical fluid flow inside the packed bed. Lim et al. [47] proposed eq. (31) to describe mass transfer correlation between fluid and solid in a packed bed.

$$
\mathrm{Sh}=f(\mathrm{Re}, \mathrm{Sc}, \mathrm{Gr})
$$

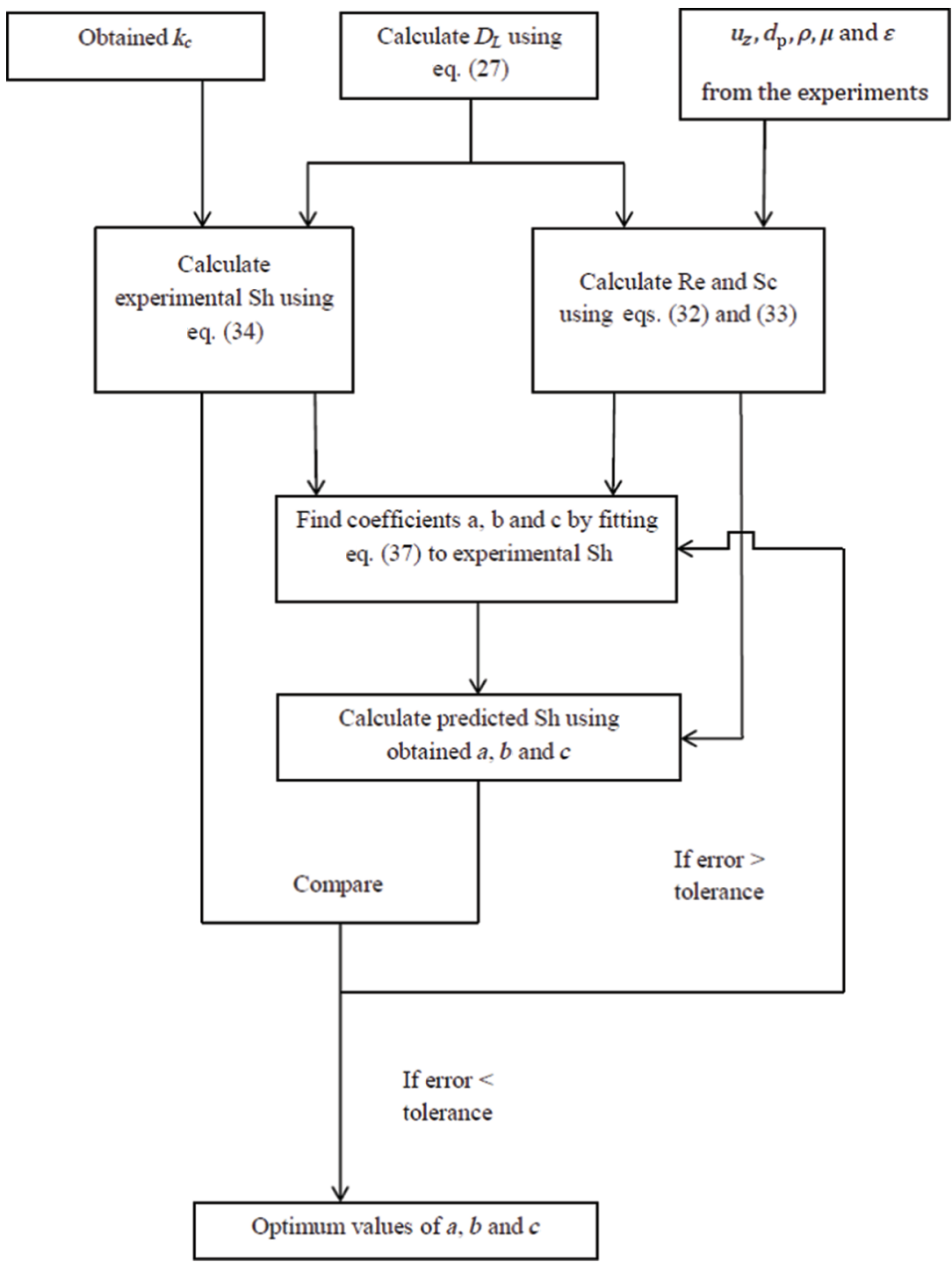

Figure 8 Procedures to obtain optimum values of mass transfer correlation parameters $(a, b$ and $c)$ 
It has been agreed that at the same Reynold number, the effect of buoyant forces in supercritical fluids is more significant compared with in normal liquids. As indicated by Debenedetti and Reid [48], the buoyant effects are one of the main factors in supercritical fluids because for the high densities or low dynamic viscosities, the fluids exhibit very small variations in kinematic viscosities. However, the effect of Reynold number is not significant when natural convective mass transfer is controlling the overall process. Therefore, mass transfer correlation becomes

$$
\mathrm{Sh}=f(\mathrm{Sc}, \mathrm{Gr})
$$

On the other hand, if forced convective mass transfer is the controlling factor, Grashof number is no longer significant and mass transfer correlation can be simplified into the following equation

$$
\mathrm{Sh}=f(\mathrm{Re}, \mathrm{Sc})
$$

Some studies suggested that generally the correlation of Sherwood, Reynold and Schmidt numbers can be expressed as follows $[49,50]$ :

$$
\mathrm{Sh}=a \operatorname{Re}^{b} \mathrm{Sc}^{c}
$$

Lim et al. [47] pointed out that above the critical pressure, forced convection is the dominant process. Therefore, in this work, forced convection was the dominant process since all experimental pressures were greater than critical pressure of $\mathrm{CO}_{2}$. Consequently, mass transfer correlation adopted in this study is eq. (37).
Experimental data and obtained mass transfer coefficients were used to calculate Sherwood, Reynold and Schmidt numbers. Then, these data were fit into eq. (37)

\begin{tabular}{|c|c|c|c|}
\hline $\begin{array}{l}\text { Operating } \\
\text { conditions }\end{array}$ & $\begin{array}{l}\text { Actual Sh } \\
\text { number } \\
\text { Sh }=\frac{k_{c} d_{p}}{D_{12}}\end{array}$ & $\begin{array}{r}\text { Predicted } \\
\text { Sh number: } \\
S h=1.14 \mathrm{Re}^{0.60} \\
\mathrm{Sc}^{0.33}\end{array}$ & $\begin{array}{r}\% \text { of error }= \\
\frac{\mid \text { Actual Sh-Predicted Sh| }}{\text { Actual Sh }} \\
\times \mathbf{1 0 0} \%\end{array}$ \\
\hline $\begin{array}{l}P=3,000 \mathrm{psi} \\
T=45^{\circ} \mathrm{C} \\
d_{p}=0.8 \mathrm{~mm} \\
Q=10 \mathrm{ml} / \mathrm{min}\end{array}$ & 410.4425 & 410.5134 & 0.0173 \\
\hline $\begin{array}{l}P=4,000 \mathrm{psi} \\
T=50^{\circ} \mathrm{C} \\
d_{p}=1 \mathrm{~mm} \\
Q=7.5 \mathrm{ml} / \mathrm{min}\end{array}$ & 306.5967 & 306.6234 & 0.0087 \\
\hline $\begin{array}{l}P=4,000 \mathrm{psi} \\
T=55^{\circ} \mathrm{C} \\
d_{p}=0.4 \mathrm{~mm} \\
Q=7.5 \mathrm{ml} / \mathrm{min}\end{array}$ & 523.4197 & 523.3823 & 0.0071 \\
\hline $\begin{array}{l}P=5,000 \mathrm{psi} \\
T=45^{\circ} \mathrm{C} \\
d_{p}=0.8 \mathrm{~mm} \\
Q=5 \mathrm{ml} / \mathrm{min}\end{array}$ & 283.5315 & 283.5291 & 0.0008 \\
\hline $\begin{array}{l}P=5,000 \mathrm{psi} \\
T=55^{\circ} \mathrm{C} \\
d_{p}=0.4 \mathrm{~mm} \\
Q=5 \mathrm{ml} / \mathrm{min}\end{array}$ & 420.1429 & 420.2172 & 0.0177 \\
\hline
\end{tabular}
according to a flowchart shown in Figure 8. These

Table 7 Actual and predicted Sherwood number

\begin{tabular}{|c|c|c|c|}
\hline Correlation & Validity & Extracted material & Reference \\
\hline $\mathrm{Sh}=1.31 \mathrm{Re}^{0.54} \mathrm{Sc}^{1 / 3}$ & $10<\operatorname{Re}<500 ; \mathrm{Sc}=1,680$ & - & Delaunay et al. [51] \\
\hline $\mathrm{Sh}=1.09 \mathrm{Re}^{0.27} \mathrm{Sc}^{1 / 3}$ & $0.055<\operatorname{Re}<3.7 ; \mathrm{Sc}=3.11 \times 10^{5}$ & - & Seguin et al. [52] \\
\hline $\mathrm{Sh}=0.82 \mathrm{Re}^{0.66} \mathrm{Sc}^{1 / 3}$ & $1<\operatorname{Re}<70 ; 3<\mathrm{Sc}<11$ & Evening primrose and roasted peanut oil & Catchpole [25] \\
\hline $\mathrm{Sh}=0.380 \mathrm{Re}^{0.83} \mathrm{Sc}^{1 / 3}$ & $2<\mathrm{Re}<40 ; 2<\mathrm{Sc}<20$ & $\beta$-naphthol & Tan et al. [53] \\
\hline $\mathrm{Sh}=0.380 \mathrm{Re}^{0.83} \mathrm{Sc}^{1 / 3}$ & - & Valeriana officinalis $\mathrm{L}$. & Salimi et al. [28] \\
\hline $\mathrm{Sh}=0.380 \mathrm{Re}^{0.83} \mathrm{Sc}^{1 / 3}$ & - & Wood & Goto et al. [24] \\
\hline $\mathrm{Sh}=0.380 \mathrm{Re}^{0.83} \mathrm{Sc}^{1 / 3}$ & - & Rosemary, basil and marjoram leaves & Reverchon et al. [54] \\
\hline $\mathrm{Sh}=0.380 \operatorname{Re}^{0.83} \mathrm{Sc}^{1 / 3}$ & $1.35<\operatorname{Re}<21.22 ; 0.004<\mathrm{Sc}<0.756$ & Carotenoids from microalgae & Macías-Sánchez et al. [29] \\
\hline $\mathrm{Sh}=0.206 \mathrm{Re}^{0.80} \mathrm{Sc}^{1 / 3}$ & $10<\mathrm{Re}<100 ; 3<\mathrm{Sc}<20$ & $\begin{array}{l}\text { 1,2-dichloro benzene and1,2,4-trichloro } \\
\text { benzene }\end{array}$ & Puiggene et al. [55] \\
\hline $\mathrm{Sh}=0.206 \operatorname{Re}^{0.80} \mathrm{Sc}^{1 / 3}$ & $4.74<\operatorname{Re}<13$ & Rapeseed, Rosehip seed and Olive Husk & del Valle et al. [27] \\
\hline $\mathrm{Sh}=0.206 \operatorname{Re}^{0.80} \mathrm{Sc}^{1 / 3}$ & - & Fig leaf gourd seed & Bernardo-Gil et al. [56] \\
\hline $\mathrm{Sh}=0.2548 \operatorname{Re}^{0.5} \mathrm{Sc}^{1 / 3}$ & $\operatorname{Re}<1 ; 70<\mathrm{Sc}<100$ & Evening primrose oil & King et al. [26] \\
\hline $\mathrm{Sh}=0.98 \operatorname{Re} S c^{1 / 3}$ & $4.32<\mathrm{Re}<4.79 ; 3.32<\mathrm{Sc}<3.84$ & Palm Oil Kernel & Norhuda et al. [30] \\
\hline $\mathrm{Sh}=3.521 \operatorname{Re} \mathrm{Sc}^{1 / 3}$ & $4.08<\operatorname{Re}<4.67 ; 2.97<\mathrm{Sc}<4.16$ & Palm Oil Kernel & Norhuda et al. [30] \\
\hline $\mathrm{Sh}=4.126 \operatorname{Re} \mathrm{Sc}^{1 / 3}$ & $3.84<\operatorname{Re}<4.51 ; 2.62<\mathrm{Sc}<3.40$ & Palm Oil Kernel & Norhuda et al. [30] \\
\hline $\mathrm{Sh}=1.14 \mathrm{Re}^{0.60} \mathrm{Sc}^{1 / 3}$ & $750<\operatorname{Re}<3,000 ; 70<S c<110$ & Sarawak black pepper & This study \\
\hline
\end{tabular}

Table 8 Benchmarks of the obtained mass transfer correlation toward existing correlations 
procedures result in the optimum values of $a, b$ and $c$ are 1.14, 0.60 and 0.33 , respectively. Therefore, mass transfer correlation is $\mathrm{Sh}=1.14 \mathrm{Re}^{0.60} \mathrm{Sc}^{0.33}$. To test the obtained Sherwood formulae, the predicted Sherwood numbers using this correlation were compared to the actual Sherwood numbers calculated from the experimental data and the obtained mass transfer coefficients. These comparisons with the percentage of error are tabulated in Table 7 and it was found that the percentage of error of the predicted Sherwood numbers are less than $0.02 \%$ compared to the actual Sherwood numbers. This correlation is also benchmarked with some existing mass transfer correlations as summarized in Table 8. The values of parameters $a, b$ and $c$ greatly vary depending on the system and validity regions. Nevertheless, the obtained correlation, $\mathrm{Sh}=1.14 \mathrm{Re}^{0.60} \mathrm{Sc}^{0.33}$, is comparable with other mass transfer correlations. Thus, this correlation is acceptable and valid for the ranges of $750<\mathrm{Re}<3,000$ and $70<$ Sc $<110$

\section{Conclusions}

Bioactive compound, namely piperine, was extracted from Sarawak black pepper using supercritical $\mathrm{CO}_{2}$ extraction. Throughout the experiments and by performing statistical analysis of the experimental data, the effects of pressures, temperatures, $\mathrm{CO}_{2}$ flow rates, particle size of black pepper and the two-factor combinations of them on the yields of pepper oil were respectively evaluated. The most effective parameters for pepper oil extraction were found to be pressure and particle size diameter. Thus, adjusting combinations of pressure and particle size can give great impact to the yield of the extraction.

Modeling and kinetic study of the supercritical extraction of black pepper oil was performed based on differential mass balance equations. These differential equations were developed to describe both internal and external mass transfer phenomena of the process. By a series of finite difference analyses and estimation of constants/parameters using empirical formulae, these equations were solved to obtain mass transfer coefficients. Mass transfer correlation was also developed and it was found that the best correlation model is $\mathrm{Sh}=1.14 \mathrm{Re}^{0.60} \mathrm{Sc}^{0.33}$ where its validity is at the ranges of $750<\operatorname{Re}<3,000$ and $70<\mathrm{Sc}<110$. These mass transfer coefficients and correlations can serve as preliminary data to scale-up supercritical $\mathrm{CO}_{2}$ extraction of bioactive compound from Sarawak black pepper.

$\begin{array}{lll}r_{c} & {[\mathrm{~m}]} & \text { Radius of particle's un-leached core } \\ \mathrm{Sh} & {[-]} & \text { Sherwood number } \\ T & {[\mathrm{~s}]} & \text { Extraction time } \\ T & {[\mathrm{k}]} & \text { Solvent temperature } \\ u_{\mathrm{z}} & {[\mathrm{m} / \mathrm{s}]} & \text { Solvent velocity } \\ V & {\left[\mathrm{~m}^{3} / \mathrm{kmol}\right]} & \text { Solute molar volume at boiling point } \\ X_{f} & {[-]} & \text { Dimensionless concentration in fluid phase, } \\ & & C_{f} / C_{\text {sat }} \\ X_{p} & {[-]} & \text { Dimensionless concentration in pores, } C_{p} / C_{\mathrm{sat}} \\ Z & {[\mathrm{~m}]} & \text { Axial coordinate of extraction column } \\ Z & {[-]} & \text { Dimensionless bed height coordinates, } z / L \\ \mathrm{Greek} & \mathrm{Letters} & \\ \beta & {[-]} & \text { Solvent association constant } \\ \varepsilon & {[-]} & \text { Bed voidage } \\ \varepsilon_{p} & {[-]} & \text { Particle void fraction } \\ \theta & {[-]} & \text { Dimensionless time, }\left(D_{\mathrm{AB}} / R^{2}\right) t \\ \mu & {[\mathrm{kg} / \mathrm{m} . \mathrm{s}]} & \text { Solvent viscosity } \\ \xi & {[-]} & \text { Dimensionless radial coordinate, } r / R \\ \xi_{c} & {[-]} & \text { Dimensionless radius of un-leached core, } r_{c} / R \\ \rho & {\left[\mathrm{kg} / \mathrm{m}^{3}\right]} & \text { Solvent density }\end{array}$

\section{Nomenclature}

\begin{tabular}{|c|c|c|}
\hline$A$ & {$\left[\mathrm{~m}^{2}\right]$} & Surface area of transfer \\
\hline $\mathrm{Bi}$ & {$[-]$} & Biot number $=k_{\mathrm{c}} R / D_{\mathrm{AB}}$ \\
\hline$C_{f}$ & {$\left[\mathrm{~mol} / \mathrm{m}^{3}\right]$} & Concentration of solute in solvent fluid \\
\hline$C_{p}$ & {$\left[\mathrm{~mol} / \mathrm{m}^{3}\right]$} & Concentration of solute in pores \\
\hline$C_{\text {sat }}$ & {$\left[\mathrm{mol} / \mathrm{m}^{3}\right]$} & Saturation concentration \\
\hline$D_{12}$ & {$\left[\mathrm{~m}^{2} / \mathrm{s}\right]$} & Molecular diffusion coefficient \\
\hline$D_{e}$ & {$\left[\mathrm{~m}^{2} / \mathrm{s}\right]$} & Effective diffusion coefficient \\
\hline$D_{L}$ & {$\left[\mathrm{~m}^{2} / \mathrm{s}\right]$} & Axial dispersion coefficient \\
\hline$d_{p}$ & {$[\mathrm{~m}]$} & Particle diameter \\
\hline$H$ & {$[\mathrm{~m}]$} & Total particle's bed height \\
\hline$k_{c}$ & {$[\mathrm{~m} / \mathrm{s}]$} & External mass transfer coefficient \\
\hline$k_{p}$ & {$[\mathrm{~m} / \mathrm{s}]$} & Overall mass transfer coefficient \\
\hline$L$ & {$[\mathrm{~m}]$} & Total length of extraction column \\
\hline$M$ & {$[\mathrm{~kg} / \mathrm{kgmol}]$} & Molar mass of solvent \\
\hline $\mathrm{Pe}$ & {$[-]$} & Peclet number, $\mathrm{Lu} / D_{L}$ \\
\hline$Q$ & {$\left[\mathrm{~m}^{3} / \mathrm{s}\right]$} & Flow rate of solvent in the extractor \\
\hline$R$ & [m] & Radius of pepper particle \\
\hline$R$ & {$[\mathrm{~m}]$} & Radius coordinate \\
\hline
\end{tabular}




\section{References}

1. Singh $\mathrm{H}$, Hasan M, Kang LL. Supercritical carbon dioxide extraction of Sarawak black pepper oil. In Proceedings of the National Symposium of Science and Technology, Kuala Lumpur, 28-30 July 2003.

2. Mysarawak. 2008. http://mysarawak.wordpress.com/2008/ 05/15/sarawak-pepper/. Accessed:5 July 2011.

3. Whfoods. 2011. http://www.whfoods.com/genpage.php? Tname=foodspice\&dbid=74. Accessed:5 Dec 2011.

4. Nutrition-and-you. 2011. http://www.nutrition-and-you.com/ black_pepper.html. Accessed:5 Dec 2011.

5. Yanishlieva NV, Marinova E, Pokorny J. Natural antioxidants from herbs and spices. Eur J Lipid Food Technol 2006;108:776-93.

6. Zougagh $M$, Valcarcel $M$, Rios A. Supercritical fluid extraction: a critical review of its analytical usefulness. Trends Anal Chem 2004;23:399-405.

7. Temelli F. Perspectives on supercritical fluid processing of fats and oils. J Supercritical Fluids 2009;47:583-90.

8. Ndocko EN, Backer W, Strube J. Process design method for manufacturing of natural compounds and related molecules. Sep Sci Technol 2008;43:642-70.

9. Herrero M, Mendiola JA, Cifuentes A, Ibanez E. Supercritical fluid extraction: recent advances and applications. J Chromatogr A 2010;1217:2495-511.

10. Lang Q, Wai CM. Supercritical fluid extraction in herbal and natural product studies - a practical review. Talanta 2001;53:771-82.

11. Pourmortazavi SM, Hajimirsadeghi SS. Supercritical fluid extraction in plant essential and volatile oil analysis. J Chromatogr A 2007;1163:2-24.

12. Sahena F, Zaidul IS, Jinap S, Karim AA, Abbas KA, Norulaini NA, et al. Application of supercritical $\mathrm{CO}_{2}$ in lipid extraction - a review. J Food Eng 2009;95:240-53.

13. Besnard M, Tassaing T, Danten Y, Andanson JM, Soetens JC, Cansell $F$, et al. Bringing together fundamental and applied science: the supercritical fluids route. J Mol Liquids 2006;125:88-99.

14. Fiori L. Supercritical extraction of grape seed oil at industrialscale: plant and process design, modeling, economic feasibility. Chem Eng Process 2010;49:866-72.

15. del Valle JM, de la Fuente JC, Cardarelli DA. Contributions to supercritical extraction of vegetable substrates in Latin America. J Food Eng 2005;67:35-57.

16. Bruner G. Supercritical fluids: technology and application to food processing. J Food Eng 2005;67:21-33.

17. Sovova H, Jez J, Bartlova M, St'astova J. Supercritical carbon dioxide extraction of black pepper. J Supercritical Fluids 1995;8:295-301.

18. Ferreira SR, Nikolov ZL, Doraiswamy LK, Meireles MA, Petenate AJ. Supercritical extraction of black pepper (Piper nigrum L.) essential oil. J Supercritical Fluids 1999;14:235-45.

19. Ferreira SR, Meireles MA. Modeling the supercritical fluid extraction of black pepper (Piper nigrum L.) essential oil. J Food Eng 2002;54:263-9.

20. Perakis C, Louli V, Magoulas K. Supercritical fluid extraction of black pepper oil. J Food Eng 2005;71:386-93.
21. Zhiyi L, Xuewu L, Shuhua C, Xiaodong Z, Yuanjing X, Yong W, et al. An experimental and simulating study of supercritical $\mathrm{CO}_{2}$ extraction for pepper oil. Chem Eng Process 2006;45:264-7.

22. Ferrerira SR, Meireles MA, Cabral FA. Extraction of essential oil of black pepper with liquid carbon dioxide. J Food Eng 1993;20:121-33.

23. Kumoro AC, Hasan M, Singh H. Extraction of Sarawak black pepper essential oil using supercritical carbon dioxide. Arabian J Sci Eng 2010;35:7-16.

24. Goto M, Smith JM, McCoy BJ. Kinetics and mass transfer for supercritical fluid extraction of wood. Ind Eng Chem Res 1990;29:282-9.

25. Catchpole 0. Supercritical packed bed extraction: a review. In Proceedings of the 6th Conference of Asia Pacific Confederation of Chemical Engineering and 21st Australasian Chemical Engineering Conference (Vol. 3, 233-236): Barton, Ed. ACT: Institution of Engineers, Australia, 1993.

26. King JW, Cygnarowwicz-Provost M, Favati F. Supercritical fluid extraction of evening primrose oil kinetic and mass transfer effects. Ital J Food Sci 1997;9:193-204.

27. del Valle JM, Germain JC, Uquiche E, Zetzl C, Brunner G. Microstructural effects on internal mass transfer of lipids in prepressed and flaked vegetable substrates. I Supercritical Fluids 2006;37:178-90.

28. Salimi A, Shohreh F, Hamzeh ZN, Asghar S. Mathematical modeling of supercritical extraction of Valerenic Acid from Valeriana officinalis L. Chem Eng Technol 2008;31:1470-80.

29. Macías-Sánchez MD, Serrano CM, Rodríguez MR, de la Ossa FM. Kinetics of the supercritical fluid extraction of caretonids from microalgae with $\mathrm{CO}_{2}$ and ethanol as cosolvent. Chem Eng J 2009;150:104-13.

30. Norhuda I, Omar AK. Mass transfer modeling in a packed bed of palm kernels under supercritical conditions. Proc World Acad Sci, Eng Technol 2009;49:173-6.

31. Supercritical Fluid Technologies. http://www.supercriticalfluids.com/prod100.htm. Accessed:8 June 2010.

32. Meireles MA. Extracting bioactive compounds for food products: theory and applications. London: CRC Press, 2008.

33. del Valle JM, de la Fuente JC. Supercritical $\mathrm{CO}_{2}$ extraction of oilseeds: review of kinetic and equilibrium models. Crit Rev Food Sci Nutr 2006;46:131-60.

34. Goto M, Roy BC, Hirose T. Shrinking-core leaching model for supercritical-fluid extraction. J Supercritical Fluids 1996;9:128-33.

35. Sediawan WB, Prasetya A. Pemodelan matematis dan penyelesaian numeris dalam teknik kimia (in Indonesian). Yogyakarta: Andi Publishing Company, 1997.

36. Geankoplis CJ. Transport processes and separation process principles (includes unit operations), 4th ed. New Jersey: Pearson Education, 2003.

37. Piperine. 2012. http://en.wikipedia.org/wiki/Piperine. Accessed: 5 Dec 2011.

38. Araus K, Uquiche E, del Valle JM. Matrix effects in supercritical $\mathrm{CO}_{2}$ extraction of essential oils from plant material. J Food Eng 2009;92:438-47.

39. Fiori L. Grape seed oil supercritical extraction kinetic and solubility data: critical approach and modelling. J Supercritical Fluids 2007;43:43-54. 
40. Spricigo CB, Bolzan A, Pinto LT. Mathematical modelling of nutmeg essential oil extraction by liquid carbon dioxide. Latin Am Appl Res 2001;31:397-401.

41. Uquiche E, del Valle JM, Ortiz J. Supercritical carbon dioxide extraction of red pepper (Capsicum annuum L.) oleoresin. J Food Eng 2004;65:55-66.

42. Reverchon E. Mathematical modelling of supercritical extraction of sage oil. AIChE J 1996;42:1765-71.

43. Akgün M, Akgün NA, Dinçer S. Extraction and modelling of lavender flower essential oil using supercritical carbon dioxide. Ind Eng Chem Res 2000;39:473-7.

44. Reis-Vasco EM, Coelho JA, Palavra AM, Marrone C, Reverchon E. Mathematical modelling and simulation of pennyroyal essential oil supercritical extraction. Chem Eng Sci 2000;55:2917-22.

45. Povh NP, Marques MO, Meireles MA. Supercritical $\mathrm{CO}_{2}$ extraction of essential oil and oleoresin from chamomile (Chaomilla recutita [L.] Rauschert). J Supercritical Fluids 2001;21:245-56.

46. Gaspar F. Extraction of essential oils and cuticular waxes with compressed $\mathrm{CO}_{2}$ : effect of extraction pressure and temperature. Ind Eng Chem Res 2002;41:2497-503.

47. Lim GB, Holder GD, Shah YT. Solid-fluid mass transfer in a packed bed under supercritical conditions. In: Johnston, KP, Penninger, JM, editors. Supercritical fluid science and technology. Washington, DC: ACS Symposium Series 406, American Society, 1989.
48. Debenedetti PG, Reid RC. Diffusion and mass transfer in supercritical fluids. AIChE J 1986;32:2034-46.

49. Çengel YA. Heat and mass transfer a practical approach, 3rd ed. Singapore: McGraw-Hill Education (Asia), 2006.

50. Welty JR, Wicks CE, Wilson RE, Rorrer GL. Fundamentals of momentum, heat and mass transfer, 5th ed. New Jersey: John Wiley \& Sons, 2008.

51. Delaunay G, Storck A, Laurent A, Charpentier JC. Electrochemical study of liquid-solid mass transfer in packed beds with upward ocurrent gas-liquid flow. Ind Eng Chem Process Design Development 1980;19:514-21.

52. Seguin D, Montillet A, Brunjail D, Comiti J. Liquid-solid mass transfer in packed beds of variously shaped particles at low Reynold numbers: experiments and model. Chem Eng J 1996;63:1-9.

53. Tan C-S, Liang S-K, Liou D-C. Fluid-solid mass transfer in a supercritical fluid extractor. Chem Eng J 1988;38:17-22.

54. Reverchon E, Donsi G, Osséo LS. Modeling of supercritical fluid extraction from herbaceous matrices. Ind Eng Chem Res 1993;32:2721-6.

55. Puiggene J, Larrayoz MA, Recasens F. Free liquid-to-supercritical fluid mass transfer in packed beds. Chem Eng Sci 1997;52:195-212.

56. Bernardo-Gil MG, Casquilho M, Esquível MM, Ribeiro MA. Supercritical fluid extraction of fig leaf gourd seeds oil: fatty acids composition and extraction kinetics. J Supercritical Fluids 2009;49:32-6. 